\title{
EFFECT OF LASER RADIATION ABSORPTION ON EFFICIENCY OF LASER WELDING OF COPPER AND ITS ALLOYS
}

\author{
V.Yu. KHASKIN ${ }^{1,2}$, V.N. KORZHIK ${ }^{1,2}$, T.G. CHIZHSKAYA ${ }^{3}$, V.N. SIDORETS ${ }^{2}$ and LO ZIE ${ }^{1}$ \\ ${ }^{1}$ Guangdong Welding Institute (Chinese-Ukrainian E. O. Paton Institute of Welding) Guangzhou, China \\ ${ }^{2}$ E.O. Paton Electric Welding Institute, NASU \\ 11 Kazimir Malevich Str., 03680, Kiev, Ukraine. E-mail: office@paton.kiev.ua \\ ${ }^{3}$ NTUU «Igor Sikorsky Kyiv Polytechnic Institute» \\ 37 Pobedy Ave., Kiev-56, Ukraine
}

\begin{abstract}
Due to a high reflection power of copper it is usually assumed that the laser welding of products of this material is not rational. However, in the modern industry the problems of joining the parts of copper and its alloys periodically arise, applying narrow welds with a deep vapor-gas channel. Moreover, for technical reasons the use of electron beam welding is not always possible and a sufficiently wide availability of fiber (wavelength of $1.07 \mu \mathrm{m}$ ) and disc (wavelength of $1.03 \mu \mathrm{m}$ ) industrial lasers of the latest generation makes the problem of laser welding of these materials challenging. Therefore, the aim of the work was to study the conditions of absorbing the laser radiation with the wavelength of $1.03-1.07 \mu \mathrm{m}$ by copper and its alloys in laser welding with a deep penetration, as well as to determine the basic parameters of the welding mode and to evaluate the process effectiveness. It was shown in the work that for certain combinations of thickness of copper alloy and density of radiation power with the wavelength of 1.03-1.07 $\mu \mathrm{m}$, the optimal speed of welding process exists, at which its technical and economic efficiency is maximum. This speed should be such that the absorbing capacity (integrated over the spot of laser heating) can be at the level of about 13-15\%. The exceeding of welding speed leads to a sharp decrease in absorbing capacity, and, consequently, to the need in increasing the radiation power and growing the cost of the process. The decrease in welding speed relatively to the optimal one leads to decrease in efficiency, overheating of metal in the weld pool and to such defects of weld shaping, as sagging and metal splashes. 11 Ref., 8 Figures.
\end{abstract}

Ke y w or d s : laser welding, copper, solid-state laser radiation, absorbing factor, radiation power, welding speed

One of the challenging problems of the modern science and engineering in the field of fusion welding of metals is the creation of new power sources, which provide the control of concentration of heat energy introduced to the metal during welding process. This ultimately allows providing the required efficiency of welding, quality of the produced welded joint, process stability and reproduction of its results. In the recent decades in capacity of such controllable heat power source for welding of metallic materials a high-concentrated laser source is ever widely applied, which is realized by thermal effect of the focused laser beam on metal being welded [1].

However, until now the regularities of influence of laser heat source on some metallic materials were studied insufficiently. In particular, such materials include copper and its alloys. Due to a high reflection power of copper it is usually assumed that the laser welding of products of this material is not rational. However, in the modern industry the problems of joining the parts of copper and its alloys periodically arise, applying narrow welds with a deep vapor-gas channel. Moreover, for technical reasons the use of electron beam welding is not always possible and a sufficiently wide availability of fiber (wavelength of $1.07 \mu \mathrm{m}$ ) and disc (wavelength of $1.03 \mu \mathrm{m}$ ) industrial lasers of the latest generation makes the problem of laser welding of these materials challenging [2].

To solve this problem it is necessary to carry out investigation of physics of the process of effect of laser heat power source on welded metal, having the high thermal conductivity and reflection power, which is copper and its alloys, to develop the appropriate mathematical models and to perform computer modeling of the mentioned process. Moreover, it is rational to evaluate the efficiency of the process of laser welding of such materials by determination of basic mode parameters, i.e. the necessary consumption of radiation power for welding at the corresponding speed.

Therefore, the aim of the work is the study of conditions of absorbing the laser radiation with the wavelength of 1.03-1.07 $\mu \mathrm{m}$ by copper and its alloys in laser welding with a deep penetration, as well as the determination of the basic parameters of welding mode and evaluation of the process efficiency.

Laser welding is characterized by the formation of a vapor-gas channel in the metal being welded. In [2] the behavior of the channel during welding is de- 
scribed in detail. In particular, it was noted that at its front wall there is a layer of molten metal, experiencing the constant "perturbations», such as the formation of distortion in the form of a step, which is periodically moved in the channel height. Moreover, the removal of material from the front wall is carried out layer-by-layer during moving the step downwards. It can be explained by the increase in molten metal layer at the front wall, occurring due to transition of radiation energy into heat energy, generated at this wall, in combination with hydrodynamic processes proceeding in the weld pool.

It is known that a part of radiation power is absorbed by the metal being welded, and a part of it is reflected from it. The volume of the absorbed radiation is higher, the higher is the metal temperature. The melt formed on the front wall absorbs radiation well, but due to the movement in the course of welding the front part of the laser beam falls all the time on the poorly heated metal, which leads to decrease in the absorbing factor. Therefore, in laser welding two processes are observed simultaneously:

- improvement of conditions of absorbing the laser radiation due to its hitting on the heated and molten metal of the front wall of the vapor-gas channel, as well as trapping of the certain volume of radiation due to its repeated reflection from channel walls;

- intensive reflection of laser radiation by a poorly heated metal, located directly ahead the vapor-gas channel in the course of welding.

To evaluate the conditions of absorbing the focused laser radiation by copper and its alloys in laser welding, let us assume that the plane specimen is heated by the heat source of high intensity and the spatial distribution of heat flow introduced to the specimen, is symmetrically relative to the axis perpendicular to its surface (relative to the laser beam axis). Let us accept the wavelength of radiation applied for welding

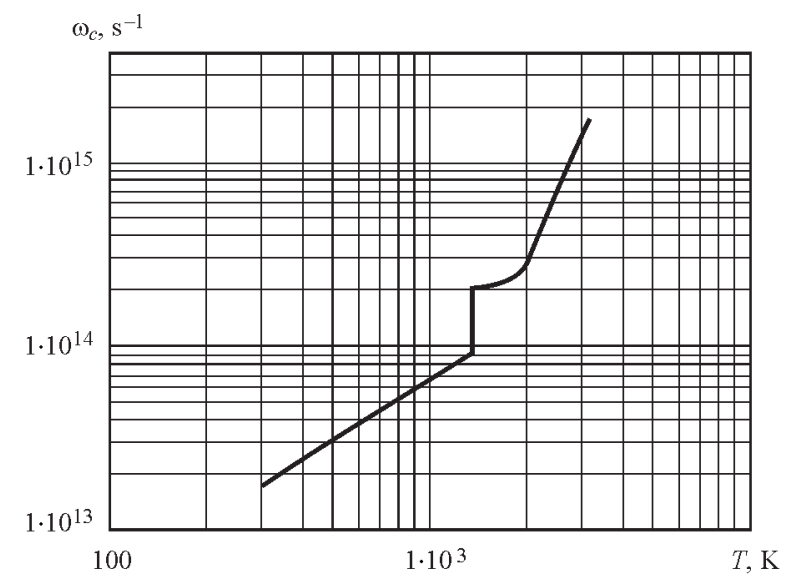

Figure 1. Dependence of relaxation frequency $\omega_{c}$ on temperature $T$ for copper of solid-state laser as equal to $\lambda=1.06 \mu \mathrm{m}$, as included into the investigated range of $1.03-1.07 \mu \mathrm{m}$.

To determine the temperature dependence of the factor of absorbing the laser radiation by metallic materials A(Ts), we will consider the investigated metal (copper) in the frames of model of almost free electrons. In this case, according to Drude-Zener [3], for the real $\varepsilon_{1}$ and imaginary $\varepsilon_{2}$ parts of the integrated permittivity of metal at the frequency of the laser radiation $\omega=2 \pi c / \lambda$, where $c$ is the light speed, $\lambda$ is the radiation wavelength, we will obtain:

$$
\begin{gathered}
\varepsilon_{1}=1-\frac{\omega_{\mathrm{p}}^{2}}{\omega^{2}+\omega_{C}^{2}} ; \\
\varepsilon_{2} \omega=4 \pi \sigma=\frac{\omega_{n} \omega_{\mathrm{p}}^{2}}{\omega^{2}+\omega_{C}^{2}} .
\end{gathered}
$$

Here $\omega_{\mathrm{p}}$ is the frequency of plasma oscillations of free electrons of metal, $\omega_{c}$ is the frequency, numerically equal to the opposite relaxation time of conduction electrons. The value of plasma frequency is determined by the formula:

$$
\omega_{\mathrm{p}}^{2}=\frac{4 \pi n e N_{\mathrm{e}}}{m_{\mathrm{e}}^{*}} ;
$$

where $e$ and $m_{\mathrm{e}}^{*}$ is the charge and effective mass of the electron in the metal [4]. The concentration of the conduction electrons $N_{\mathrm{e}}=V / \Omega$ is determined though the valence $V$ and the atomic volume $\Omega$. The value of the valence for copper was accepted as equal to two. The atomic volume was obtained on the basis of experimental data by density of copper, given in the work [5].

In the limiting case of a constant field, when $\omega=0$, the high-frequency optical conductivity $\sigma$ is converted into static conductivity of the metal:

$$
\sigma(0)=\frac{N_{\mathrm{e}} e}{m_{\mathrm{e}} \omega_{c}} .
$$

The temperature dependence of relaxation frequency $\omega_{c}$ for the considered metals in the solid state was calculated by the following formula [6]:

$$
\omega_{c}=K^{\prime} T^{5} \int_{0}^{\theta / T} \frac{z^{4} d z}{e^{z}-1},
$$

where $\theta$ is the Debye temperature. The values $\omega_{c}$ and, accordingly, $K^{\prime}$ at room temperature for copper were selected in accordance with the data of the work [7]. For copper in the liquid state the experimental values from the works [8, 9] were used. The calculation data obtained in such a way are shown in Figure 1.

The temperature dependence presented in this Figure, has a characteristic gap at the melting temperature of metal $T_{\mathrm{m}}$. According to the formulae (1) and (2) using (3)-(5) the temperature dependences of the real and imaginary parts of the integrated permittivity 


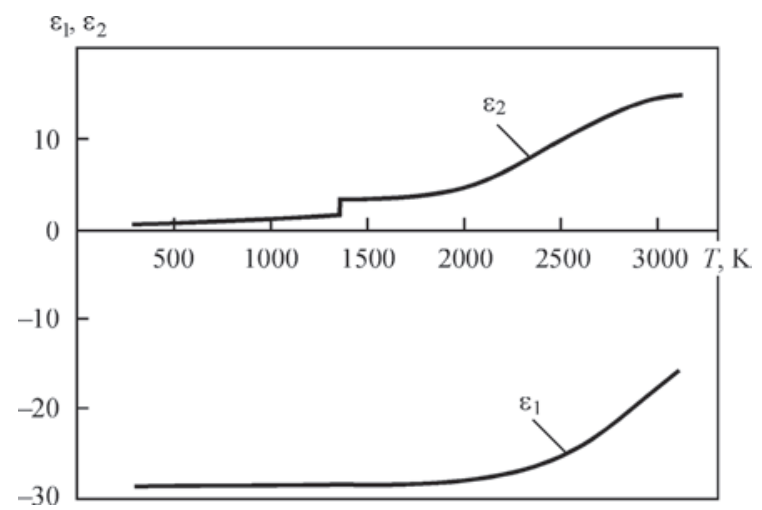

Figure 2. Dependences of real $\varepsilon_{1}$ and imaginary $\varepsilon_{2}$ parts of integrated permittivity of copper on temperature $T$ at frequency of radiation of solid-state laser $(\lambda=1.06 \mu \mathrm{m})$

for copper at the frequency of solid-state laser radiation $(\lambda=1.06 \mu \mathrm{m})$ were plotted, shown in Figure 2 (here and further, the temperature is expressed in Kelvin degrees).

For the further calculations it is convenient to introduce the real $n$ and imaginary $k$ parts of the complex refractive index of metal at the frequency of laser radiation

$$
\sqrt{\varepsilon}=\sqrt{\varepsilon_{1}+i \varepsilon_{2}}=n+i k
$$

using the following formulae for this:

$$
\begin{aligned}
& n=\sqrt{\frac{\sqrt{\varepsilon_{1}^{2}+\varepsilon_{2}^{2}}+\varepsilon_{1}}{2}}, \\
& k=\sqrt{\frac{\sqrt{\varepsilon_{1}^{2}+\varepsilon_{2}^{2}}-\varepsilon_{1}}{2}} .
\end{aligned}
$$

The temperature dependences of the real and imaginary parts of the complex refractive index for copper are shown in Figure 3.

Using the obtained values $n$ and $k$, let us determine the laser absorbing factor, normally falling on the plane metal surface (absorbing capacity), according to the known formula

$$
A=\frac{4 n}{(1+n)^{2}+k^{2}} .
$$

In some cases the more important parameter is the reflection factor (reflectance), which can be determined according to the formula

$$
R=1-A=\frac{(1-n)^{2}+k^{2}}{(1+n)^{2}+k^{2}} .
$$

Figure 4 shows the results of calculations of temperature dependences of the absorbing factor of radiation of solid-state laser for copper in the range from room to boiling temperatures of metal $T_{\mathrm{b}}$ and higher.

The calculation dependence of absorbing capacity, obtained for the selected type of radiation, was compared with the available experimental data [6-9] and the matching was quite satisfactory. According to the dependence, shown in Figure 5, to achieve the maximum values of absorbing factor of the surface

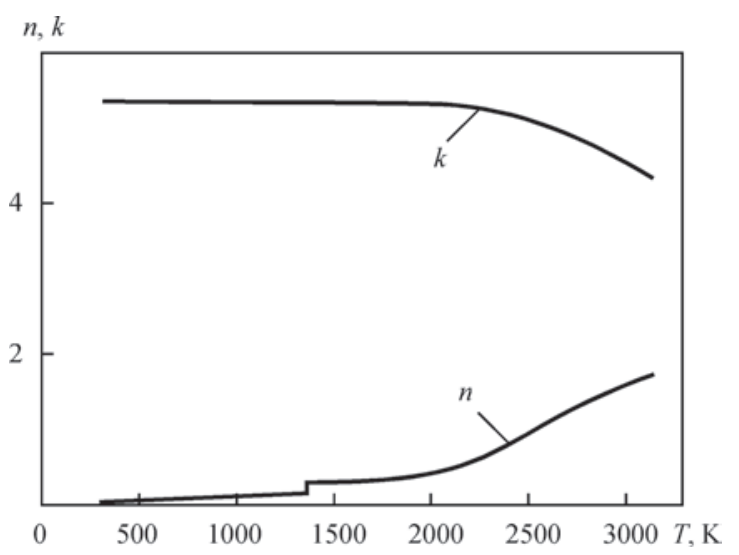

Figure 3. Dependences of real $n$ and imaginary $k$ part of the integrated refractive index of copper on temperature $T$ at frequency of radiation of solid-state laser $(\lambda=1.06 \mu \mathrm{m})$

of the welded copper alloy in the zone of acting laser radiation with the wavelength of $1.06 \mu \mathrm{m}$, it should be heated to boiling temperature $T_{b}$. However, even heating to melting temperature $T_{\mathrm{m}}$ is sufficient for an abrupt jumpy increase in absorbing capacity from $2.0-2.5$ to $4.5-5.0 \%$.

To determine the temperature distributions in the depth and on the surface of the copper specimen welded using focused laser radiation, the calculation using the method of finite differences was conducted involving an implicit difference scheme. For this purpose the software product of the own development was applied, based on the computational and experimental methods, described in the work [10]. During calculations the thermophysical characteristics of copper were used given in the work [11]. The data obtained in the process of computer modeling were compared with the experimental results. While conducting the latter, the disc laser of the model TruDisk 10002 (company TRUMPF, Germany) was applied with the capacity of up to $10.0 \mathrm{KW}$. To move the welding head, the robot of the model KR $60 \mathrm{HA}$ (the company KUKA, Germany) was used. Welding of specimens of copper of the type M1 of size $100 \times 50 \times 3 \mathrm{~mm}$ was performed in argon shielding with deposition and

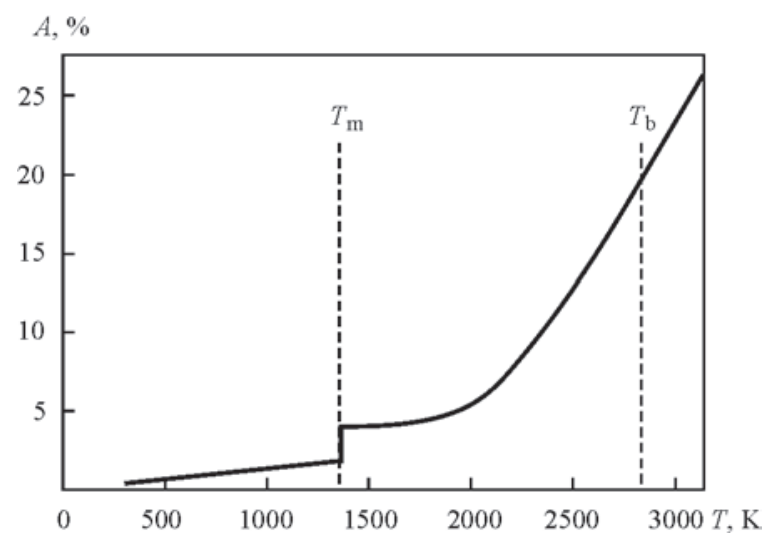

Figure 4. Dependences of absorbing capacity $A$ of copper on temperature $T$ for radiation with wavelength of $1.06 \mu \mathrm{m}$ 

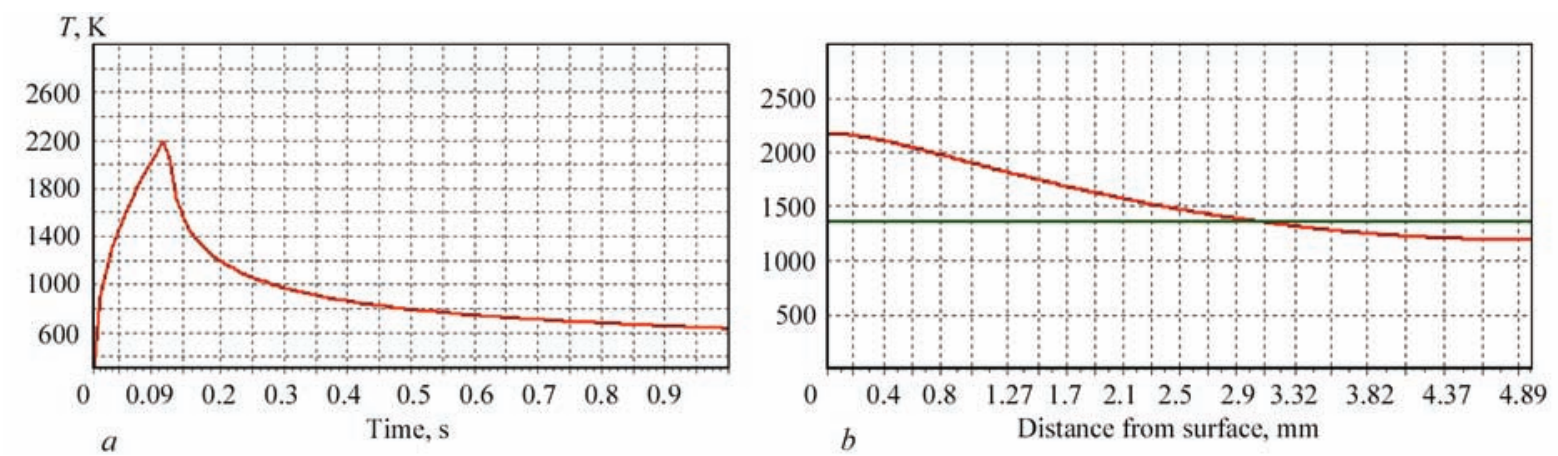

Figure 5. Distribution of temperatures $T$ on the surface $(a)$ and in the depth $(b)$ of copper plate of 5 mm thickness in laser welding using radiation of solid-state laser $(A=13 \%)$ with density of power $4.5 \cdot 10^{7} \cdot \mathrm{W} / \mathrm{cm}^{2}$ and speed $v_{\mathrm{w}}=90 \mathrm{~m} / \mathrm{h}(25 \mathrm{~mm} / \mathrm{s})$
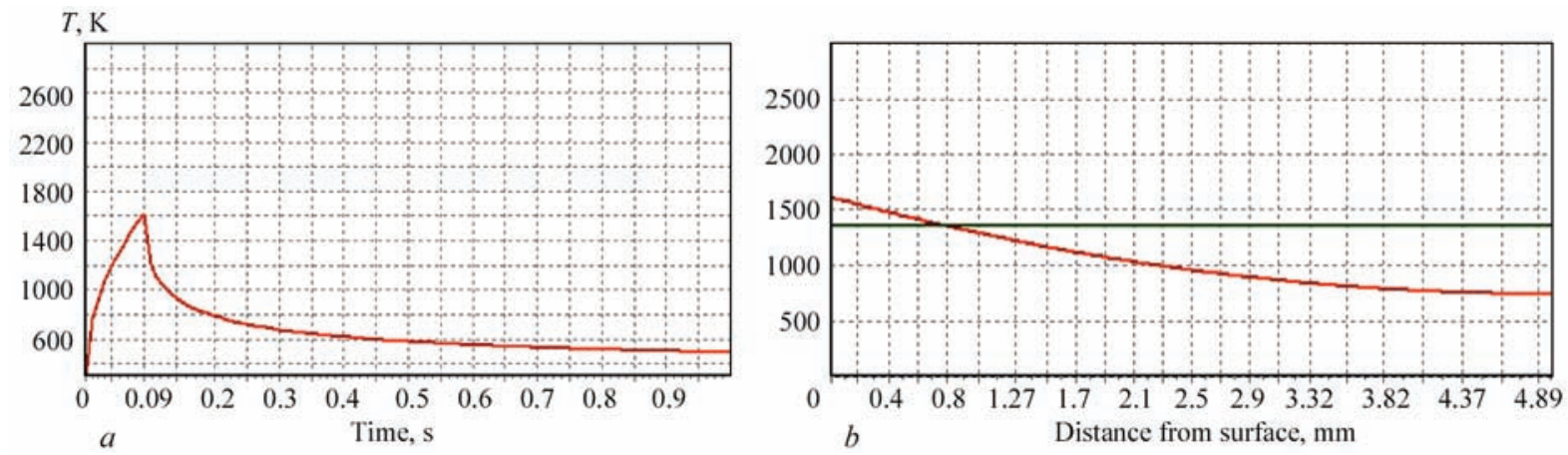

Figure 6. Distribution of temperatures $T$ on the surface $(a)$ and in the depth $(b)$ of copper plate of $5 \mathrm{~mm}$ thickness in laser welding using radiation of solid-state laser $(A=10 \%)$ with density of power $4.5 \cdot 10^{7} \mathrm{~W} / \mathrm{cm}^{2}$ and speed $v_{\mathrm{w}}=120 \mathrm{~m} / \mathrm{h}(33.3 \mathrm{~mm} / \mathrm{s})$

butt welds at the density of laser radiation power of $4.5 \cdot 10^{7} \mathrm{~W} / \mathrm{cm}^{2}$.

The investigations show that for the fixed thickness of penetrated specimen (in this case $\delta=3 \mathrm{~mm}$ ) it is possible to select such welding speed $v_{\text {opt }}$ at which not more than one third of the length of heat source (i.e. diameter of laser radiation) acts constantly on the solid surface of copper, located directly ahead the vapor-gas channel during welding. In this region the absorbing capacity of the surface A changes from 2.0 to $5.0 \%$. Approximately two thirds of the length of the heat source (i.e. diameter of laser radiation) will fall in this case to the vapor-gas channel, the temperature in which reaches not lower than $2900 \mathrm{~K}$, and the absorbing capacity is 19-20\%. Such welding speed amounts to about $v_{\text {opt }} \leq 25 \mathrm{~mm} / \mathrm{s}(90 \mathrm{~m} / \mathrm{h})$. It provides the absorbing capacity in the range of 13-15\% integrated on the spot of laser heating. In this case, the penetration depth will amount to not less than $3 \mathrm{~mm}$ (see Figure 5).

With increase in welding speed $v_{\mathrm{w}} \geq v_{\mathrm{opt}}$ the volume of laser power, falling to the region of a low absorbing capacity, will increase and a part of this energy, falling to the region with a high absorbing capacity, on the contrary, will decrease. This will result in decrease of integrated absorbing capacity of less than $13 \%$ and, consequently, in need of increasing the laser radiation power. The last moment will result in increase in the cost of running meter of weld and the corresponding decrease in technical and economic efficiency of the
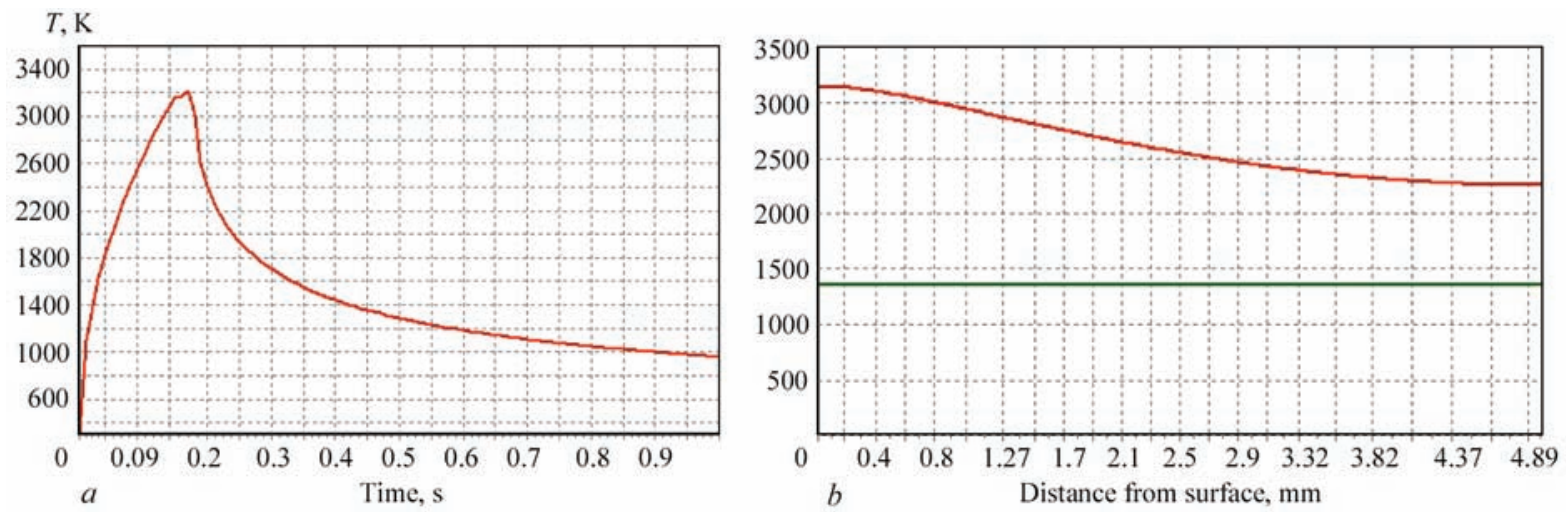

Figure 7. Distribution of temperatures $T$ on the surface $(a)$ and in the depth $(b)$ of copper plate of 5 mm thickness in laser welding using radiation of solid-state laser $(A=17 \%)$ with density of power $4.5 \cdot 10^{7} \mathrm{~W} / \mathrm{cm}^{2}$ and speed $v_{\mathrm{w}}=60 \mathrm{~m} / \mathrm{h}(16.7 \mathrm{~mm} / \mathrm{s})$ 
process. In this case, the penetration depth is much smaller than the required $3 \mathrm{~mm}$, which will lead to the lack of penetration (Figure 6).

With decrease in welding speed relatively to the selected one $\left(v_{\mathrm{w}} \leq v_{\mathrm{opt}}\right)$ the greater part of radiation will fall to the vapor-gas channel, and absorbing capacity will increase by more than $15 \%$. However, in this case the process efficiency will decrease $\left(v_{\mathrm{w}} \leq 16.7 \mathrm{~mm} / \mathrm{s}\right.$ or $\left.v_{\mathrm{w}} \leq 60 \mathrm{~m} / \mathrm{h}\right)$, and it will become less effective. In this case, the penetration depth will significantly exceed the required $3 \mathrm{~mm}$, which will result in such shaping defects as sagging and splashes of the weld metal (Figure 7).

To perform the experimental verification of the predicted results of laser welding on plane specimens the surfacing welds were produced, then the penetration depth was measured on macrosections and compared with the calculation data. In addition, at the calculation modes the butt joints were welded (Figure 8). Such verification allowed establishing that the calculation accuracy amounts to about 5-8 \%, which in the case of technological calculations is a satisfactory indicator.

Thus, the study of conditions of absorbing the laser radiation with the wavelength of 1.03-1.07 $\mu \mathrm{m}$ in welding with deep penetration of copper and its alloys allows stating that for a certain combination of welding material thickness and density of radiation power, such an optimal process speed exists, at which its technical and economic efficiency is maximum. This speed corresponds to the integrated one over the spot of laser heating of absorbing capacity of about $13-15 \%$. The exceeding of welding speed leads to a sharp decrease in absorbing capacity, and, consequently, to the need in increasing the radiation power and growing of the process cost. The decrease in welding speed relatively to the optimal one leads to the decrease in efficiency, overheating of metal in the weld pool and to such defects of weld shaping, as sagging and metal splashes.

The work was carried out at the support of the Foreign Experts Program of China No. WQ20124400119,
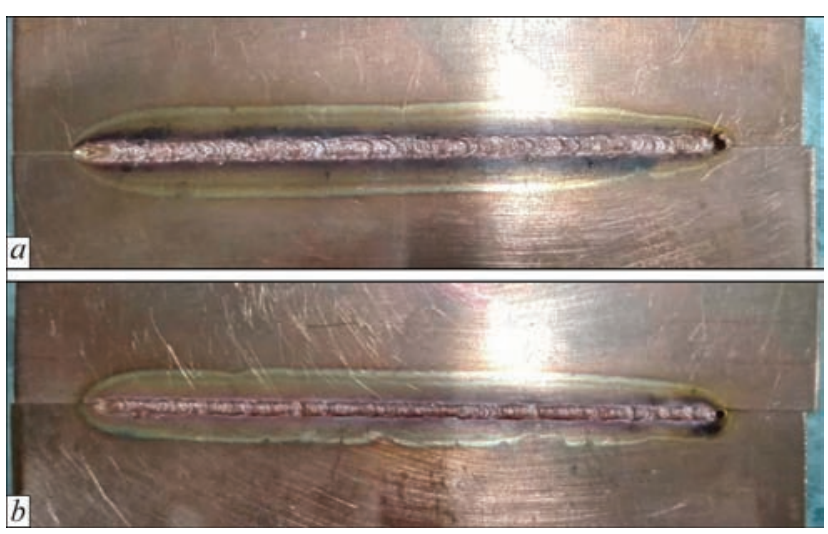

Figure 8. Butt joint of sheet copper M1 $(\delta=3 \mathrm{~mm})$ produced by laser welding in argon using radiation of power density $4.5 \cdot 10^{7} \mathrm{~W} /$ $\mathrm{cm}^{2}$ and speed $v_{\mathrm{w}}=90 \mathrm{~m} / \mathrm{h}(25 \mathrm{~mm} / \mathrm{s}): a$ - top; $b$ - bottom

Program of the Innovation Group of the Province Guangdong, China No. 201101C0104901263, Guangdong research Project No. 2015A050502039, Guangdong research Project No. 2016 B050501002.

1. Grigoryants, A.G., Shiganov, I.N. (1988) Laser equipment and technology. Book 5: Laser welding of metals. Manual for inst. of higher education. Ed. by A.G. Grigoryants. Moscow: Vysshaya Shkola.

2. Bernadsky, V.N., Shelyagin, V.D., Makovetskaya, O.K. (2007) Present market of laser equipment for welding and processing of materials. The Paton Welding J., 10, 44-49.

3. Noskov, M.M. (1983) Optical and magnetooptical properties of metals. Sverdlovsk: UNTs AN SSSR.

4. Kiselev, A.I., Akashev, L.A., Kononenko, V.I. (2004) Effective mass of electrons in melts of aluminium, cesium and Al-3 at.\% Ce binary system. Zh. Tekhnicheskoj Fiziki, 74(Issue 3), 20-23.

5. Zinoviev, V.E. (1989) Thermophysical properties of metals at high temperatures: Refer. Book. Moscow: Metallurgiya.

6. Ujihara, K. (1972) Reflectivity of metals at high temperatures. J. of Applied Physics, 43(5), 2376-2383.

7. Ordal, M.A., Long, L.L., Bell, R.J. et al. (1983) Optical properties of the metals $\mathrm{Al}, \mathrm{Co}, \mathrm{Cu}, \mathrm{Au}, \mathrm{Fe}, \mathrm{Pb}, \mathrm{Ni}, \mathrm{Pd}, \mathrm{Pt}, \mathrm{Ag}, \mathrm{Ti}$ and $\mathrm{W}$ in the infrared and far infrared. Applied Optics, 22(7), 1099-1119.

8. Miller, J. (1969) Optical properties of liquid metals at high temperatures. Phil. Mag., Vol. 20, 12(Issue 168), 1115-1132.

9. Comins, N.R. (1972) The optical properties of liquid metals. Ibid., 25(Issue 4), 817-831.

10. Khaskin, V.Yu. (2012) Experiment-calculated method for determination of conditions of laser surfacing processes. Nauka ta Innovatsii, 8(6), 5-16. 